
reprints@futuremedicine.com

\title{
Time for a systematic approach to the treatment of hepatitis $C$ virus infection in injection drug users
}

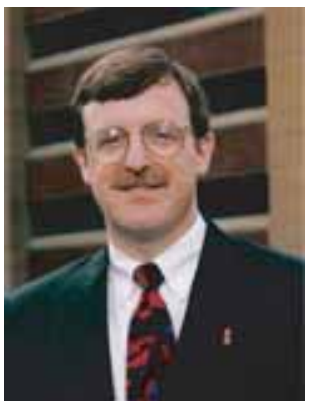

Brian Canwayt, Jason Grebdy \& Fiona Duncan

${ }^{\dagger}$ Author for correspondence Pender Community $\mathrm{H}$ ealth Centre, Vancouver Coastal H ealth, Vancouver, Canada and,

University of

British Columbia,

D epartment of

Anaesthesiology,

Pharmacology

and Therapeutics,

201-1200 Burrard Street,

Vancouver, BC V6Z 2C7,

Canada

Tel.: +1 604642 6429;

Fax: +1 604642 6419;

bconway@interchange.ubc.ca

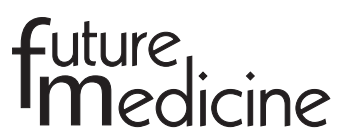

'As IDUs constitute the bulk of the HCV epidemic in developed countries, it is quite clear that a ny comprehensive approach to control this epidemic must include a systematic strategy to address this group. The development of such programsmay be quite complex, but the ultimate benefit...is c erta inly worth the effort.'

The spread of injection drug use (ID U) has led to an explosive epidemic of hepatitis $C$ virus ( $\mathrm{HCV}$ ) infection in many urban populations. Of the estimated 123 million prevalent cases in the world, more than $50 \%$ occur in ID Us, with over $75 \%$ of incident infections being associated with this high-risk behavior, representing over 200,000 new cases each year in the USA alone [1]. O nly $20 \%$ of these patients or fewer will clear their viremia spontaneously (usually within the first year following infection), with the remainder progressing to chronic disease and serving as a reservoir for the further spread of infection [2].

Pharmacological advances have led to the development of $\mathrm{HCV}$ treatment regimens with improved efficacy, resulting in a virological cure in $50 \%$ of patients receiving once-weekly pegylated interferon (PEG-IFN) in combination with twice-daily ribavirin for 24-48 weeks, a figure that exceeds $80 \%$ (with only 24 weeks of treatment) in a subgroup of individuals carrying H CV genotype 2 or 3 infection [3]. In the past, clinical guidelines have excluded IDU s from being considered for therapy unless they had been free of IDU for at least 6 months. This approach is still in place in many centers, despite the fact that guidelines promoted by the $\mathrm{N}$ ational Institutes of $\mathrm{H}$ ealth in 2002 advocate the broader consideration of active IDUs on an individual basis [101]. Concerns over patient motivation and adherence, medical and psychiatric comorbidity, reinfection due to recurrent risk behaviors, and the lack of infrastructure to ensure long-term access to care, have all been raised as obstacles to the initiation of $\mathrm{HCV}$ treatment in this population [4].
Preliminary reports from some centers have confirmed that many IDUs may be likely to consider treatment if this is coupled with a comprehensive approach to their medical and psychiatric requirements (including a systematic addiction treatment program) within existing infrastructures [5]. How do we move forward from these positive, anecdotal reports to a more systematic approach to meet the needs of the millions of IDU s living with this condition, not to mention the hundreds of thousands that will become infected in the next year?

The first simple measure is to raise awareness in the affected population. A recent study has demonstrated that as many as $80 \%$ of infected ID U s would be motivated to receive treatment if it were made available to them [6]. This desire may well extend to a broader population of IDUs of unknown HCV status, who, upon being informed of the availability of a potentially curative treatment, would come forward to be tested.

'A recent study has demonstrated that as many as $80 \%$ of infected IDUs would be motivated to receive treatment if it were made available to them.'

In fact, in our own center we were able to determine that $64 \%$ of our population was infected with HCV and that $45 \%$ of these carried genotype 2 or 3 infection [7]. This was a pleasant surprise, as it indicates that a significant minority of our patient population could receive a 24-week treatment course with a high expected cure rate. We think this information will help us engage even larger numbers of individuals in care. 0 ur results should al so provide the impetus for other centers to conduct systematic surveys of their patient populations to help plan for the implementation of treatment programs.

The second measure is to develop pilot programs for the treatment of H CV in selected individuals in a way that will maximize the probability of success and allow the identification of necessary criteria for their scale-up. In our center, HCV-infected IDUs who were 
viremic, noncirrhotic, with alanine transferase (ALT) levels more than 1.5-times the upper limit of normal (ULN) and in whom there was a reasonable expectation of adherence to therapy were offered 24-48 weeks (based on H CV genotype) of combination therapy with ribavirin along with IFN - $\alpha 2 \mathrm{~b}(1.5 \mu \mathrm{g} / \mathrm{kg}$ three-times weekly) replaced by PEG-IFN- $\alpha 2 b(1.5 \mu \mathrm{g} / \mathrm{kg}$ once weekly) as it became available [8]. Staff administered all injections under direct observation. In total, 37 patients (31 males) received therapy with IFN- $\alpha 2 b$ (12 patients) or PEG -IFN - $\alpha 2 b$ (25 patients), 20 with genotype 2 or 3 infection (54\%). The mean baseline age, body weight, ALT and duration of infection were 42 years, $83 \mathrm{~kg}, 170 \mathrm{U} / \mathrm{l}$ and 13 years. O nly 11 patients discontinued therapy early $(30 \%)$. 0 verall end-of-treatment response was $70 \%$ (26 out of 37 ), $85 \%$ (17 out of 20 ) in subjects with genotype 2 or 3 infection. O veral the 16 patients receiving the entire course of PEG IFN-based therapy had a maximal virological response. Pretreatment drug abstinence and illicit drug use during treatment did not have a significant impact on response rates, as long as interventions were available to prevent the drug use from becoming regular. It is quite encouraging to see that a number of pilot studies in Australia, Europe and the USA [5] have already generated results similar to our own. Further study is required to evaluate the sustained virological responses in larger numbers of individuals, but our results certainly suggest that, in the right setting, response rates in IDUs can approach those reported in clinical trials of combination therapy for HCV infection. The key will be to identify systematically which components of the program will be needed to ensure its success, a concept that will likely vary according to the center and its specific population.

Finally, it will be important that these programs be implemented within research protocols to ensure their rigorous design and evaluation.
An important concern remains the risk of reinfection with $\mathrm{HCV}$ after treatment. If this were high, it could rapidly negate the benefit of any therapeutic interventions.

'...our results certa inly suggest that,

in the right setting, response rates in

IDUscan a pproach those reported in clinic al trials of combination therapy for HCV infection.'

We have already begun to compare the incidence of HCV infection in those having spontaneously cleared their viremia with those who were documented to be previously uninfected [7]. HCV reinfection was documented in 14 out of $152(9.2 \%)$ individuals or an incidence rate of 1.8 cases per 100 personyears. In contrast, new infections were documented in 172 out of 926 (18.6\%) individuals, at a much higher rate of 8.1 cases per 100 person-years. These data are consistent with those generated in a cohort of IDUs in Baltimore, M D, USA [9]. Although we have not yet identified the mechanism of the protective effect of prior infection, we will be able to design studies to establish this as well as to see if the reduced rate of reinfection extends to those who have cleared infection while on treatment compared with those who have spontaneously cleared viremia. In the meantime, these data reassure us that we should continue to develop our treatment programs while these questions are being addressed.

As IDU s constitute the bulk of the HCV epidemic in developed countries, it is quite clear that any comprehensive approach to control this epidemic must include a systematic strategy to address this group. The development of such programs may be quite complex, but the ultimate benefit (for the treated population and for society as a whole) is certainly worth the effort.
Bibliography

1. Shepard CW, Finelli L, Alter M J: Global epidemiology of hepatitis $C$ virus infection. Lancet Infect. D is. 5, 558-567 (2005).

2. Thomas DL, Seeff LB: $N$ atural history of hepatitis C. Clin. Liver D is. 9, 383-398 (2005).

3. Hughes CA, Shafran SD: $C$ hronic hepatitis $C$ virus management: 2000-2005 update. Ann. Pharmacother. 40(1), 74-82 (2006).
4. Edlin BR, Seal KH, Lorvick J et al.: Is it justifiable to withhold treatment for hepatitis $C$ from illicit-drug users? N. Engl. J. M ed. 345, 211-214 (2001).

5. Dore GD, Thomas DL: $M$ anagement and treatment of injection drug users with hepatitis C virus (H CV) infection and $\mathrm{HCV}$ /human immunodeficiency virus coinfection. Semin. Liver Dis. 25(1), 18-32 (2005).
6. Strathdee SA, Latka M H , C ampbell JV et al.: Factors associated with interest in initiating treatment for hepatitis $\mathrm{C}$ virus (H CV) infection among young H CVinfected injection drug users. Clin. Infect. D is. 40(S5), S304-S312 (2005).

7. Grebely J, Conway B, Raffa J, Lai C, K rajden $M$, Tyndall $M$ W : $N$ atural history of hepatitis $C$ virus infection among injection users in Vancouver, C anada. Proceedings of the 56 th Annual M eeting of 
the American Association for the Study of Liver Disease. San Francisco, CA, U SA, 11-15 N ovember 2005.

8. Grebely J, M eagher $C$, D uncan $F$ et al.: Treatment of hepatitis $C$ virus (HCV) infection in injection drug users (IDUs) using directly observed therapy (D OT). Proceedings of the HEP D ART Conference: Frontiers in D rug D evelopment in Viral $\mathrm{H}$ epatitis. Kohala C oast, $\mathrm{H}$ awaii, 11-15 D ecember 2005.

9. Mehta SH, Cox A, H oover DR, et al.: Protection against persistence of hepatitis C. Lancet 359(9316), 1478-1483 (2002).
Website

101. N ational Institutes of $\mathrm{H}$ ealth C onsensus D evelopment Program: $M$ anagement of hepatitis (2002).

http://consensus.nih.gov/2002/2002

H epatitisC 2002116html.htm

Affiliations

- Brian Conway

Pender Community $\mathrm{H}$ ealth Centre,

Vancouver Coastal $\mathrm{H}$ ealth,

Vancouver, Canada

and,

University of British Columbia,

D epartment of Anaesthesiology,

Pharmacology and Therapeutics,

201-1200 Burrard Street,

Vancouver, BC V6Z 2C7,

Canada

Tel.: +1 6046426429 ;

Fax: +1 604642 6419;

bconway@interchange.ubc.ca
- Jason Grebely

University of British Columbia,

D epartment of Anaesthesiology,

Pharmacology and Therapeutics,

201-1200 Burrard Street,

Vancouver, BC V6Z 2C7,

Canada

Tel.: +1 604642 6429;

Fax: +1 604642 6419;

jgrebely@interchange.ubc.ca

- Fiona D uncan

Pender Community $\mathrm{H}$ ealth Centre, Vancouver Coastal $\mathrm{H}$ ealth,

59 West Pender Street,

Vancouver, BC V6X 2A9,

Canada

Tel.: +1 604669 9181;

Fax: +1 604688 9575;

fiona.duncan@vch.ca 